\title{
Ribbed glass fiber reinforced plastic rebar embedded in concrete - an experimental study
}

Journal of Composite Materials 47(17) 2125-2132

(C) The Author(s) 2012

Reprints and permissions: sagepub.co.uk/journalsPermissions.nav DOI: $10.1177 / 0021998312454690$ jcm.sagepub.com

SAGE

\author{
JP Morales Arias, MM Escobar and A Vazquez
}

\begin{abstract}
The experimental program developed in this work aims at investigating the bond behavior of glass fiber reinforced plastic embedded in concrete. Different types of surface treatment were applied to the smooth rods in order to enhance the bond with concrete. Firstly, the rods were machined using a lathe and a grinding stone to create lugs with different configurations. The experimental results indicate that the bond strength is highest when the failure mode is a combination of two mechanisms: shearing off of the concrete lugs and that of the FRP lugs. With regard to the variation of rib width, the friction and interlock forces have a greater influence on bond strength. With respect to the height of the rib, the variation of internal diameter does not affect significantly the bond strength. Secondly, the machined rods were coated with sand fixed with a thin layer of epoxy resin. The incorporation of the sand on the surface increases the bond strength compared with the results obtained without sand.
\end{abstract}

\section{Keywords}

Glass fiber reinforced plastic, concrete, ribbed bars

\section{Introduction}

Significant efforts and resources have been devoted to condition assessment, rehabilitation and repair of deteriorating infrastructure. The main cause of deterioration of existing reinforced concrete structures is the corrosion of the steel reinforcement. ${ }^{1}$

Fiber-reinforced plastic (FRP) materials are under widespread investigation as an improved method of concrete reinforcement, due to their potential promise of improved durability in comparison with conventional steel materials. ${ }^{2}$ Other favorable properties of FRP reinforcing bars include: high strength/weight ratio, electromagnetic neutrality and ease of handling. The performance of reinforced concrete that utilizes FRP bars depends primarily on the properties of the bond between the reinforcement and the surrounding concrete. An adequate level of bonding is required between those two components to transmit forces from one to the other.

The replacement of steel bars with FRP ones changes the mechanism of load transfer between the concrete and the reinforcement. This is because FRP materials are anisotropic, thus the resin is responsible for the shear and transverse properties whereas the longitudinal properties are dependent on the fibre. ${ }^{3}$

Some of the more commonly accepted operative mechanisms of bond in $\mathrm{FRP} /$ concrete systems are chemical adhesion, friction due to radial pressure and interlock at a microscopic level and mechanical interlock which resembles friction but at a much larger scale. ${ }^{4}$ The degree to which any one of these mechanisms controls bond behavior is strongly dependent of the design of the FRP rods. One way to increase the mechanical interlock involves surface deformations and sand particle coating. ${ }^{2}$ Within surface deformation, we can distinguish between machined rods or wrapped rods. In the former, a lathe is used to introduce axisymmetrical surface configurations, and in the later, the rod is wrapped with fiber, which has previously been impregnated with resin, during the pultrusion process. ${ }^{5}$

Grupo de Polímeros y Materiales Compuestos, CP II27AAR Buenos Aires

Corresponding author:

MM Escobar, Grupo de Polímeros y Materiales Compuestos INTECIN - CONICET, Las Heras 22I4-CP I I27AAR Buenos Aires.

Email: mescobar@fi.uba.ar 
Figure 1 shows schematically the possible load-slip curves for a concrete specimen reinforced with a FRP bar during a pull-out test whose surface was modified by using ribs and sand particles. ${ }^{6}$ Due to shear stress distribution along the embedment length, during a pullout test, debonding of the FRP bar would start at $F_{A}$ and would complete at $\mathrm{F}_{\mathrm{B}}$, for all the three cases in Figure 1. So, for low bond-forces values, $F<F_{B}$, the bond efficiency is assured mostly by chemical adhesion, and no bar slip occurs. Curve $I$ represents the case when the applied load continues to increase even after the completion of debonding at $\mathrm{F}_{\mathrm{B}}$.

This increase is attributed to the bearing resistance, caused by mechanical interlocking of the surfaces of the concrete and the bar, and frictional resistance, caused by the bar's surface roughness. Also, in deformed bars the ribs induce transverse microcracks that originate at the tips of the ribs allowing the bar to slip, but the wedging action of the ribs remains limited and there

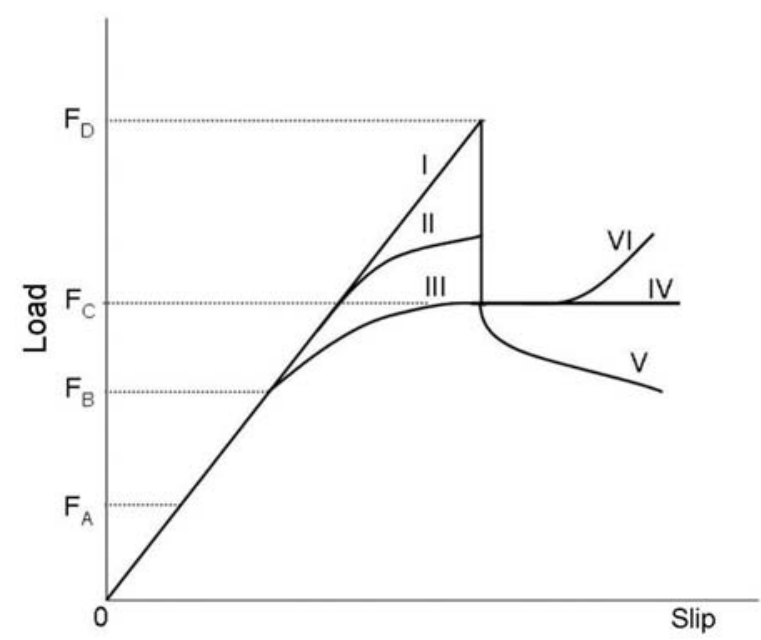

Figure I. A schematic of load versus slip behavior during single fiber direct pull-out test. is no concrete splitting. ${ }^{7}$ When the ribs or the sand particles along the entire embedment length are sheared at the maximum load $\mathrm{F}_{\mathrm{D}}$, the bearing resistance due to them is eliminated and the load drops suddenly to the frictional force, $\mathrm{F}_{\mathrm{C}}$. Alternatively, shearing of ribs and sand particles can be progressive as observed in this study. Curve III represents the case when the shearing of ribs or sand particles is complete before reaching the maximum load. Curve II represents the case when the shearing is partial and hence, a load drop is registered at the maximum load due to the sudden shearing of the remaining intact ribs or sand particles.

Bond behavior between FRP rebars and concrete has been studied by several authors. ${ }^{8-11}$ More recently, Lee et al. ${ }^{12}$ found that the interfacial bond strength of glass fiber reinforced polymer (GFRP) bars embedded in concrete increases as the compressive strength of concrete increases. Also, they stated that bond failure of the GFRP bar can occur either by crushing/splitting of concrete or by delamination of the resin-rich outer layer away from the fiber core in the bar. Davalos et al. ${ }^{13}$ studied the effect of FRP bar degradation on interface bond with high strength concrete. They found that the FRP bars can absorb water and swell, which increased the mechanical interlocking and friction with concrete, resulting in an increase of bond strength. In order to study the influence of the surface geometry of the bars on the bond strength, Baena et al. ${ }^{14}$ described the geometric parameter $a_{s}$, defined as the ratio of the projected rib area normal to the axis to the centre to centre rib spacing (Figure 2). They claimed that higher bond strength was obtained with higher values of $a_{s}$. Al-mahmoud et al. ${ }^{15}$ have done an excellent study investigating the influence of the geometry of machined ribbed bars on the bond strength in terms of another geometrical parameter, CLR. The CLR ratio is defined as the ratio between the concrete rib width, $\mathrm{w}_{\mathrm{c}}$, and the sum of the widths of the concrete rib and FRP rebar rib, $w_{c}+w_{f}$ (Figure 2). They stated that the ultimate

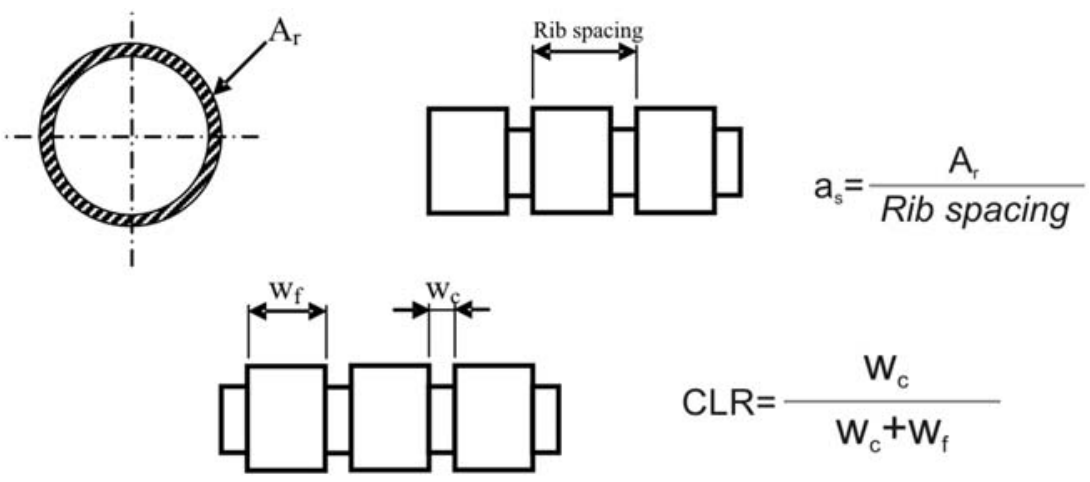

Figure 2. Definition of the "area to space ratio" $\left(a_{s}\right)$ and the "concrete rib ratio" (CLR). 
bond strength of the rods increases as the CLR increases.

In order for FRP bars to become widely accepted in the construction industry, all aspects of their structural behavior must be studied to guarantee their widespread application will be risk free. In contrast to steel, there is yet no standardization for the surface characteristics of FRP bars. Therefore, determining the bond characteristics of non-standard commercial rebars is a fundamental requirement for their widespread acceptance by civil industry.

The objective of this work is to present a systematic study of the influence that the geometry of ribbed GFRP bars has on the bond strength and their load transfer mechanism when embedded in concrete. This work compares the all geometric parameters used recently in literature $\left(C L R\right.$ and $\left.a_{s}\right)$. The effect of sand coating the ribbed bars and the subsequent impact on bond strength was also studied.

\section{Experimental}

\section{Materials}

The unidirectional glass bars were fabricated employing the pultrusion process, using unsaturated polyester orthophtalic type resin as matrix and glass fiber type $\mathrm{E}$ as reinforcement. The fiber content was $60 \mathrm{wt} \%$. The external diameter of the bars was $16 \mathrm{~mm}$. The glass temperature $\left(T_{\mathrm{g}}\right)$ of the unsaturated polyester was $50^{\circ} \mathrm{C}$. The tensile strength and Young's modulus were $680 \mathrm{MPa}$ and $41.4 \mathrm{GPa}$, respectively, according to manufacturer specifications.

\section{Bars conditioning}

A turning lathe and a grinding stone were used to machine ribs with different geometries in order to investigate their effects on the bond strength between the rebar and the concrete. The geometrical parameters of the ribs considered in this study were internal diameter $\left(\mathrm{d}_{\mathrm{c}}\right)$, the width of the machined ribs $\left(\mathrm{w}_{\mathrm{f}}\right)$ and the distance between machined ribs $\left(\mathrm{w}_{\mathrm{c}}\right)$. In order to characterize the global geometry of the ribs, two parameters were used: $a_{s}$ : area to space ratio and $C L R$ : Concrete Lug Ratio ${ }^{14,15}$ (Figure 1).

The study was divided in two parts. The first one considered the variation in the width of the ribs $\left(\mathrm{w}_{\mathrm{f}}\right)$. Table 1 indicates the different geometries studied. In order to study the influence of $\mathrm{w}_{\mathrm{f}}$, the distance $\mathrm{w}_{\mathrm{f}}+\mathrm{w}_{\mathrm{c}}$ was fixed at $14 \mathrm{~mm}$. The internal diameter was fixed at $14 \mathrm{~mm}$ in all experiments. The second part involved investigating the influence of the internal diameter, $d_{c}$, on bond behavior. On the completion of the study into rib widths, the configuration w-8-8 was selected for the remaining tests. The internal diameter was varied between 9 and $15 \mathrm{~mm}$ with an increase of $1 \mathrm{~mm}$ (Table 2).

Each one of the twelve configurations previously described were also coated with coarse sand and embedded in the concrete matrix. The rebars were cleaned by sandpaper to remove the rust on their surface before coating. The bars were sand blasted with coarse sand using an epoxy adhesive of two components (Diglycidylether of bisphenol-A with $\mathrm{n}=0.14-$ DGEBA) as pre-polymer and triethylenetetramine as hardener agent (TETA), from Huntsman Chemical and imported by Distraltec S.A., Argentina). According to ASTM A 775 (Specification for EpoxyCoated Reinforcing Steel Bars), the coating thickness should be in the range of $130-300 \mu \mathrm{m}$. The $T_{\mathrm{g}}$ of the

Table 2. Denomination of each bar with different internal diameters $\left(d_{c}\right)$

\begin{tabular}{|c|c|}
\hline Name & $\mathrm{d}_{\mathrm{c}}(\mathrm{mm})$ \\
\hline $\mathrm{d}-9$ & 9 \\
\hline $\mathrm{d}-10$ & 10 \\
\hline $\mathrm{d}-11$ & 11 \\
\hline $\mathrm{d}-12$ & 12 \\
\hline $\mathrm{d}-13$ & 13 \\
\hline $\mathrm{d}-14$ & 14 \\
\hline $\mathrm{d}-15$ & 15 \\
\hline
\end{tabular}

Table I. Denomination of each bar with different geometries

\begin{tabular}{|c|c|c|c|c|}
\hline Name & $\mathrm{w}_{\mathrm{c}}(\mathrm{mm})$ & $\mathrm{w}_{\mathrm{f}}(\mathrm{mm})$ & $\mathrm{a}_{\mathrm{s}}$ & $\mathrm{CLR}$ \\
\hline $\mathrm{W}-4-12$ & 4 & 12 & 2,95 & 0,33 \\
\hline $\mathrm{w}-6-10$ & 6 & 10 & 2,95 & 0,6 \\
\hline $\mathrm{w}-8-8$ & 8 & 8 & 2,95 & 1 \\
\hline $\mathrm{w}-10-6$ & 10 & 6 & 2,95 & 1,66 \\
\hline $\mathrm{w}-12-4$ & 12 & 4 & 2,95 & 3 \\
\hline
\end{tabular}


epoxy system is $110^{\circ} \mathrm{C}$. According to our previous work, ${ }^{16}$ the better results were obtained when the covering was of sand obtained through sieving (sieve $\mathrm{N}^{\circ} 16$ $(1.18 \mathrm{~mm})$, according to ASTM C 778-02.)

\section{Methods}

The bond between bars and concrete was evaluated by pull-out test (Figure 3). This method was chosen because it is simple and leaves the free end accessible for the slip to be measured. The pull-out tests were performed according to ACI 440.3R-04 standard.

The pull-out specimens were prepared with a cylindrical mould with a diameter of $100 \mathrm{~mm}$ and height of $200 \mathrm{~mm}$. The concrete used for the pull-out test specimens was prepared in the laboratory and the composition is given in Table 3. The FRP bars were embedded in a concrete matrix, which had a mean 28-day compressive strength of $43 \mathrm{MPa}$.

The FRP bars were concentrically embedded in the concrete cylinders. In order to control the bond length, the FRP bar was prepared with a bond breaker, which

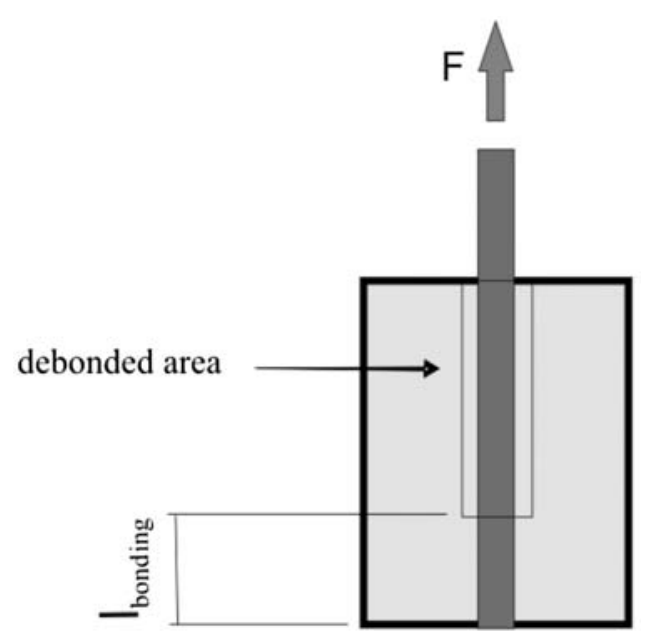

Figure 3. Scheme of pull-out setup.

Table 3. Concrete formulation

\begin{tabular}{|c|c|}
\hline Material & $\mathrm{Kg} / \mathrm{m}^{3}$ \\
\hline CPF 40 Av & 9240 \\
\hline Water & 4792 \\
\hline Fine Sand & 16217 \\
\hline Crushed Sand & 10945 \\
\hline Coarse Agregate 6-20mm & 37053 \\
\hline
\end{tabular}

consisted of soft plastic tubing inserted around the bar to prevent contact of FRP with concrete. The embedment length was five times the bar diameter. The concrete cylinder specimens, with embedded FRP, were removed from the metallic moulds one day after casting, and stored for 27 days in a confined room $\left(\mathrm{T}^{\circ}: 20^{\circ} \mathrm{C}\right.$ and $\left.\mathrm{RH}: 75 \%\right)$. The tests were performed using a servo-hydraulic testing machine with a capacity of $200 \mathrm{kN}$. Displacement control was selected to capture post-peak behaviour. The load was applied to the reinforcement bar at a rate of $0.02 \mathrm{~mm} / \mathrm{s}$ and measured with the electronic load cell of the testing machine. The loaded and unloaded end slips were measured with four linear variable differential transducers (LVDT). An automatic data acquisition system was used to record the data.

It is well known that the strength distribution is not constant along the embedment length. In order to make the analysis easier, we utilized an average bond strength defined as:

$$
\tau=\frac{P}{\pi d_{b} l_{b}}
$$

where $P$ is the tensile load, $d_{b}$ is the rebar diameter and $l_{b}$ is the embedment length. The shear strength is defined as the pull-out load divided by the interface area between the ribs and the rods.

After the pull-out test, splitting tensile strength tests of cylindrical concrete specimens were performed according ASTM C496 in order to carry out a visual examination of the actual bond failure mode. Each bond strength value represents the average of the results for at least three specimens.

\section{Results}

Variation of $w_{c}$

Smooth ribbed bar. Figure 4 shows the typical bond strength versus free-end slip curves of smooth ribbed bars included in concrete. In this figure, only one representative curve is reported for each configuration, that closer to the average. It is observed that the freeend slip did not start until a threshold shear strength value was reached. Taking into account the maximum bond strength achieved by the samples, better performance was noted in the w-8-8 sample, reaching $9 \mathrm{MPa}$ (Figure 4(c)).

The other four curves can be divided in two groups: (a) the first includes the w-4-12 and w-6-10 samples, in which a bond strength plateau is observed after the maximum peak bond strength is reached (Figure 4(a) and (b)); (b) the second one includes the w-10-6 and w-12-4 samples, in which a sudden drop in the bond strength is observed after reaching the maximum 
(curves $\mathrm{d}$ and $\mathrm{e}$ ). In the case of $\mathrm{w}-8-8$ sample, a small plateau of bond strength was observed followed by a sudden drop, showing an intermediate behavior between the patterns of behaviour observed in the two cases mentioned before.

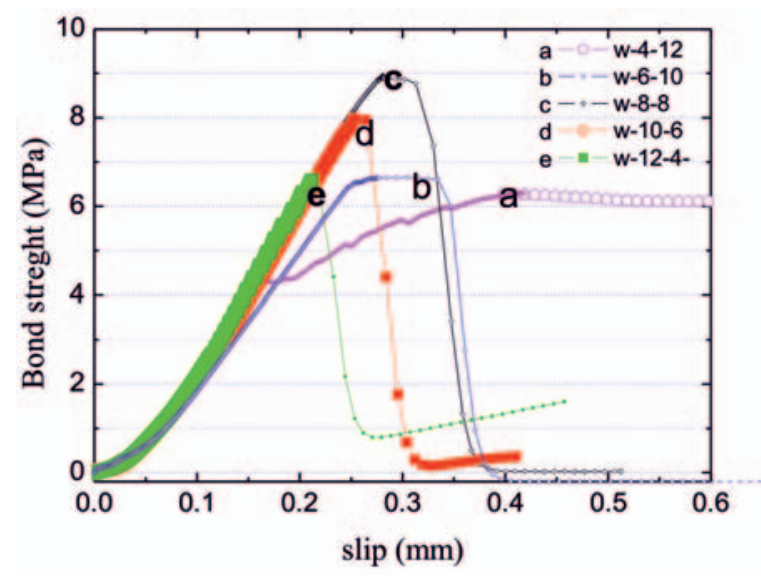

Figure 4. Bond strength versus slip of smooth ribbed bars: (a) w-4-12, (b) w-6-10, (c) w-8-8, (d) w-10-6 and (e) w-12-4.
Figure 5 shows the samples after the splitting test in order to demonstrate the failure mode. It was observed that the failure mode depends strongly on the geometry of the ribs. In the case of w-4-12 and w-6-10 samples, the failure occurs by the shearing off of the concrete ribs (Figure 4(a) and (b)). According to Soong, ${ }^{6}$ the shape of the curve represents the case when the shearing is partial and hence a load drop is registered at the maximum load due to the sudden shearing of the remaining intact ribs. After the failure, the main mechanism to resist the pull-out is the friction between the cylindrical surface and the concrete. This is the cause of the bond strength plateau observed for curves (a) and (b) in Figure 4.

In the cases of w-10-6 and w-12-4, the failure mode consisted of the shearing off of the FRP ribs (Figure 5(d) and (e)). When the ribs along the entire embedment length are sheared at the maximum load $\mathrm{F}_{\mathrm{D}}$, the bearing resistance due to them is eliminated and the load drops suddenly to the frictional force, $\mathrm{F}_{\mathrm{C}}$. In this case, frictional force tends to zero.

Clearly, When the failure mode is the shearing off the GFRP ribs (cases 4-12 and 6-10), the bond strength
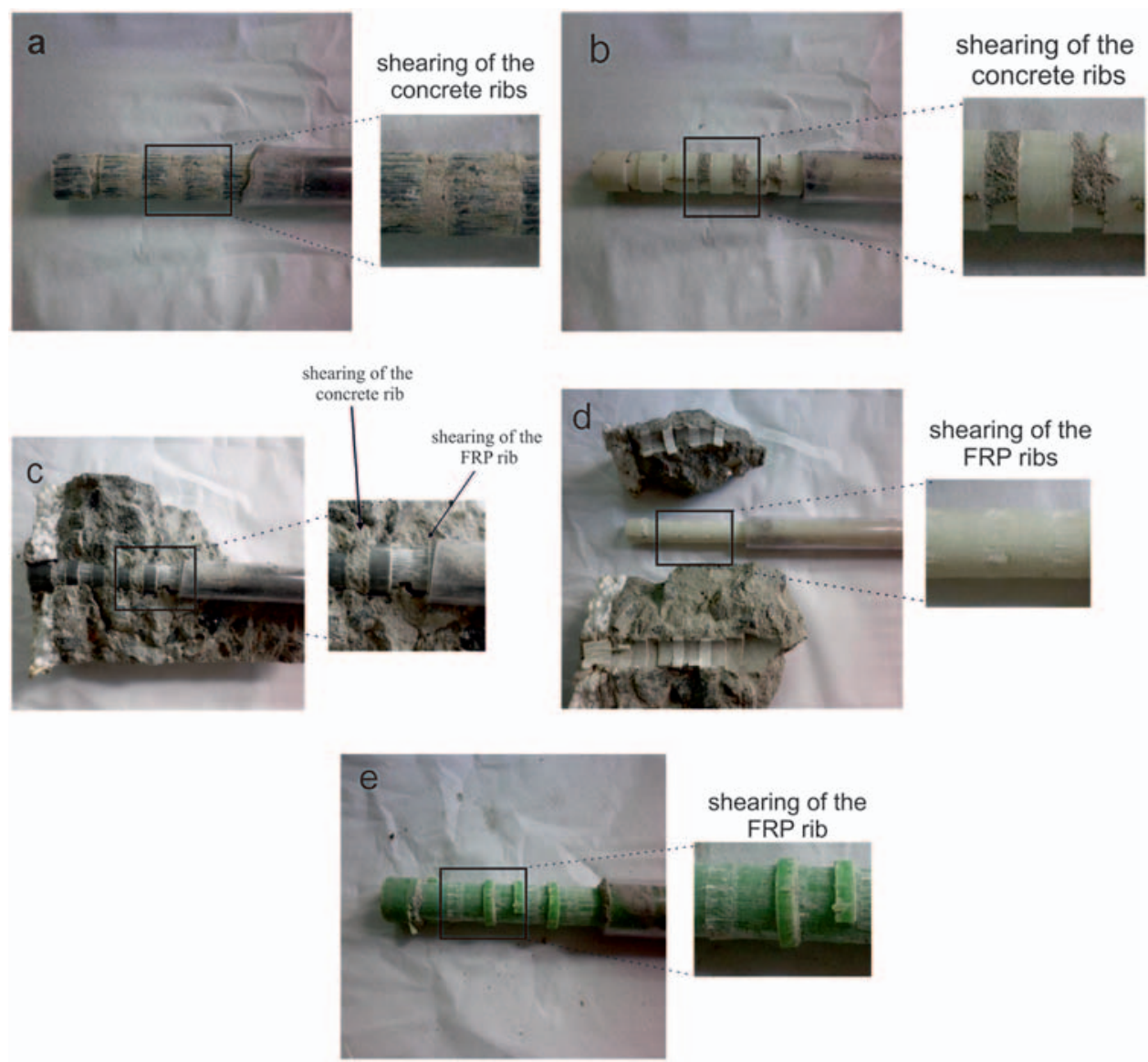

Figure 5. Photograph of smooth ribbed bars after splitting test (a) w-4-12, (b) w-6-10, (c) w-8-8, (d) w-10-6 and (e) w-I2-4. 
is dependent on the shear strength of resin matrix; when the failure mode is the shearing off the concrete lugs (cases 12-4 and 10-6), the bond strength is dependent on the shear strength of concrete.

In the case of sample w-8-8, it can be observed an intermediated behavior between both modes: as the distribution of stress is not uniformly dispersed, the ribs of FRP furthest away from the free load extreme were sheared off whereas the ribs closest to the free load extreme maintained their structure (Figure 5(c)).

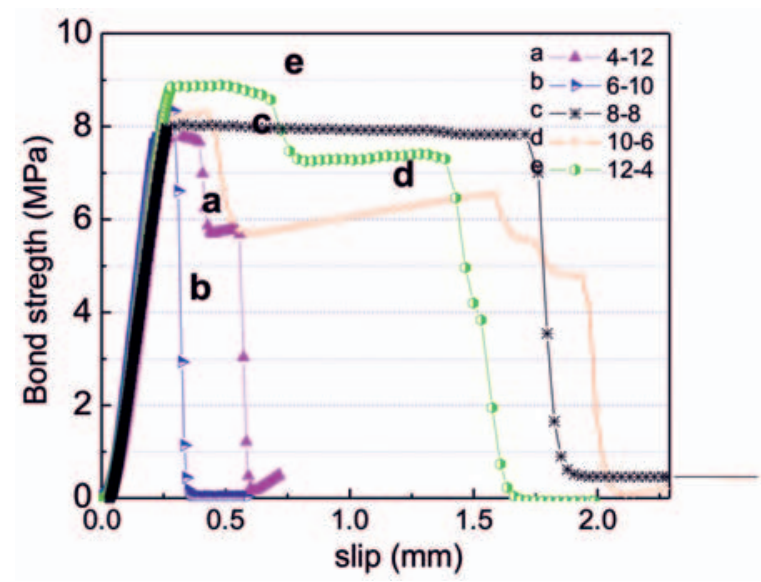

Figure 6. Bond strength versus slip of sanded ribbed bars: (a) w-4-12, (b) w-6-10, (c) w-8-8, (d) w-10-6 and (e) w-12-4.
Sanded ribbed bars. Figure 6 shows the bond strength versus slip of the ribbed bars coated with sand. In this figure, only one representative curve is reported for each configuration, that closer to the average. They presented a quite different behavior respect of that observed to smooth bars.

The bond failures of sanded w-4-12 and w-6-10 were relatively brittle. The sudden free-end slip was accompanied by significant energy release. During that short moment, there was no data recorded and the pullout resistance seemed to be reduced to almost zero.

Taking into account the maximum bond strength developed by the samples, the best performance corresponds to the $\mathrm{w}-12-4$, achieving close to $9 \mathrm{MPa}$. In the cases of samples w-4-12 and w-6-10 (curves $a$ and $b$ ), a sudden drop in the bond strength is observed after the maximum value is reached. In the case of the smooth ribbed with the same geometry, they presented a prolonged plateau after reaching the maximum value.

In the cases of samples w-10-6 and w-12-4, an extended plateau in the bond strength is observed (curves $d$ and $e$ ). In the case of sample w-8-8, there was a lower bond strength peak, followed by an extended plateau.

After the pull-out test, all samples with sanded ribbed bars failed due to splitting of concrete. Figure 7 shows clearly that the chemical adhesion between the concrete and bars is very strong when the
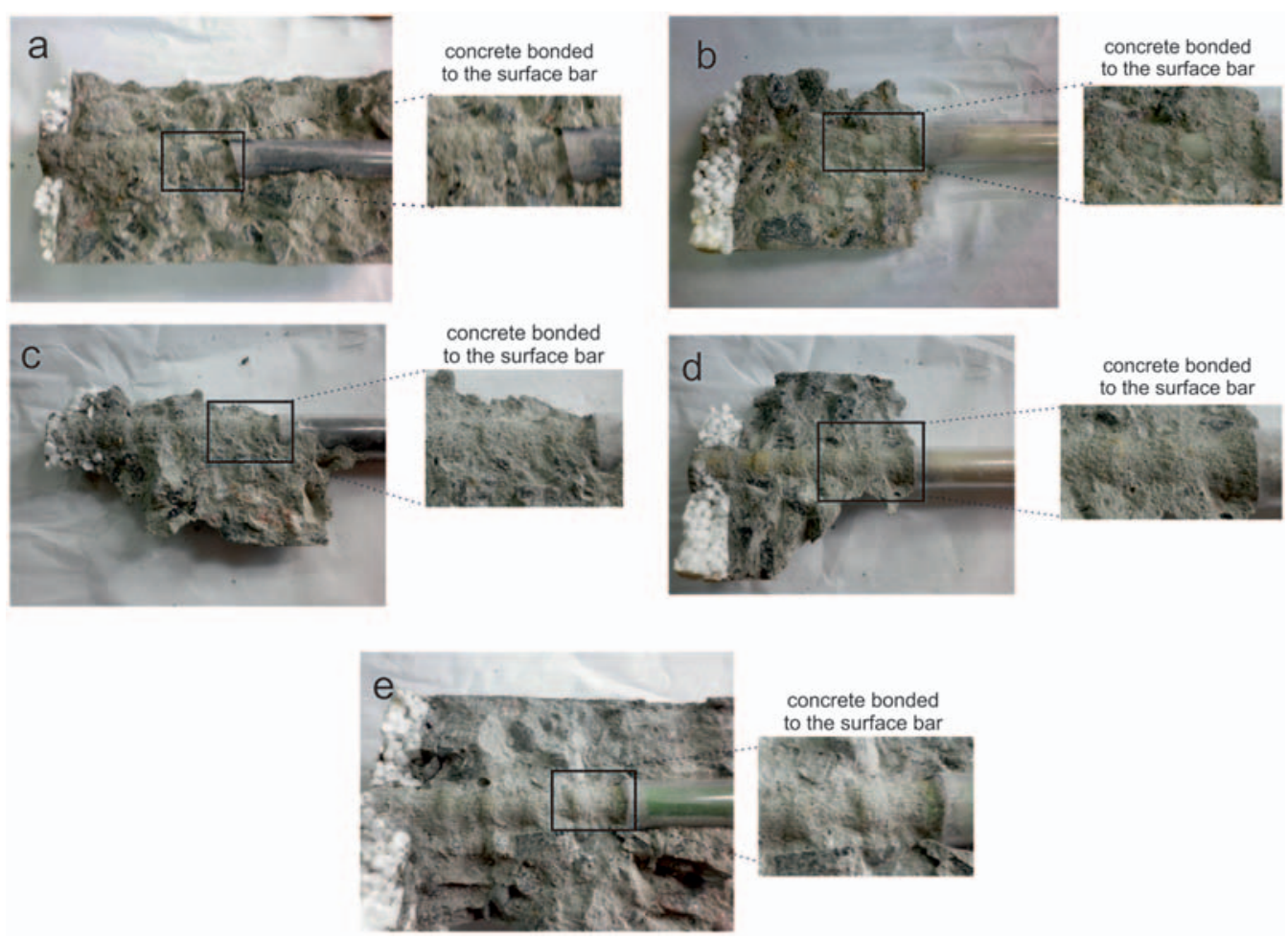

Figure 7. Photograph of sanded ribbed bars (a) w-4-12, (b) w-6-10, (c) w-8-8, (d) w-10-6 and (e) w-12-4. 
coating of sand is present. Concrete remained bonded to the surface bar after the splitting test. In these cases, the failure mode doesn't depend on the geometry of the ribs. The sand on the surface improves the interface behavior, providing a more efficient friction mechanism and a better anchoring mechanism. The contribution from chemical bonding to the measured pullout load is always present, but in the case of smooth bar, it plays a minor role.

Several authors have analyzed the influence of the rebar geometry by looking at two geometric ratios parameters: $a_{\mathrm{s}}$ and CLR. ${ }^{14,15}$ They found that increasing the CLR increases the ultimate bond strength of the rods. In the present work, we present a systematic study on CLR ratio, keeping constant the $\mathrm{a}_{\mathrm{s}}$ parameter (Table 1).

Al-mahmoud et al. ${ }^{15}$ stated that a CLR of 0.35 is sufficient to ensure a bond strength equivalent to that of ribbed steel bar. Also, they state that when failure occurs by the shearing off of the FRP ribs, better bond strength was achieved prior to failure.

Figure 8 shows the bond strength versus CLR parameter for both smooth and sanded machined bars. In the case of smooth bars, the best performance was achieved by the configuration of CLR 1 . For sanded bars, the maximum bond strength corresponds to the bars whose CLR was 3. For each configuration, it can be seen that the coating of sand improved the adhesion between the bar and concrete, except in the case of CLR of 1 . The variations in performance were directly related with the different failure mechanisms, as has been noted in the previous section.

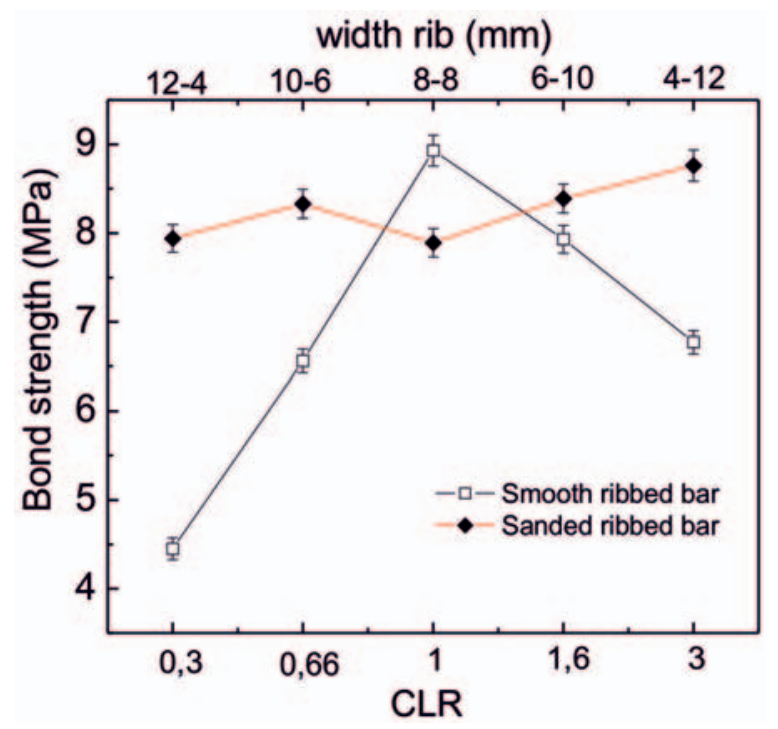

Figure 8. Peak values of bond stress of smooth and sanded ribbed bar versus concrete rib ratio (CLR) ratio.
Variation of $d_{c}$

Smooth ribbed bars. For the samples d-9, d-10 and d-11, the bars failed when the pull-out load was higher than the tensile strength of the ribbed bars.

When the ribs of GFRP were lathed, some glass fibers have been cut. So the shear strength of at the surface of GFRP rods has been reduced. Figure 9 shows the bond strength versus slip in ribbed bars of different internal diameter embedded in concrete. In general, all peak values are within a short range of bond strength. However, some differences can be observed after the splitting test. For cases d-12, d-13 and $\mathrm{d}-14$, the failure mode was shearing off of ribs. The system d-14 reached a slightly higher value of bond strength. After the failure, the friction is the main mechanism that resists the pull-out forces. The higher the value of $d_{c}$ is, the smaller the plateau that is reached after the peak value of bond strength. For the case $\mathrm{d}-15$, the failure mode is the splitting of concrete. In this case, after the maximum bond strength is reached, a sudden drop in the bond strength is observed.

Sanded ribbed bars. Figure 10 shows the bond strength versus slip for sanded ribbed bars of different internal diameter embedded in concrete. It is observed that the coating of sand drastically modifies the bond behavior with respect to results described in the previous section. The sand provides a better anchorage mechanism through chemical adhesion and interlocks mechanism. For the cases d12, d13 and d15, the samples failed by splitting of concrete.

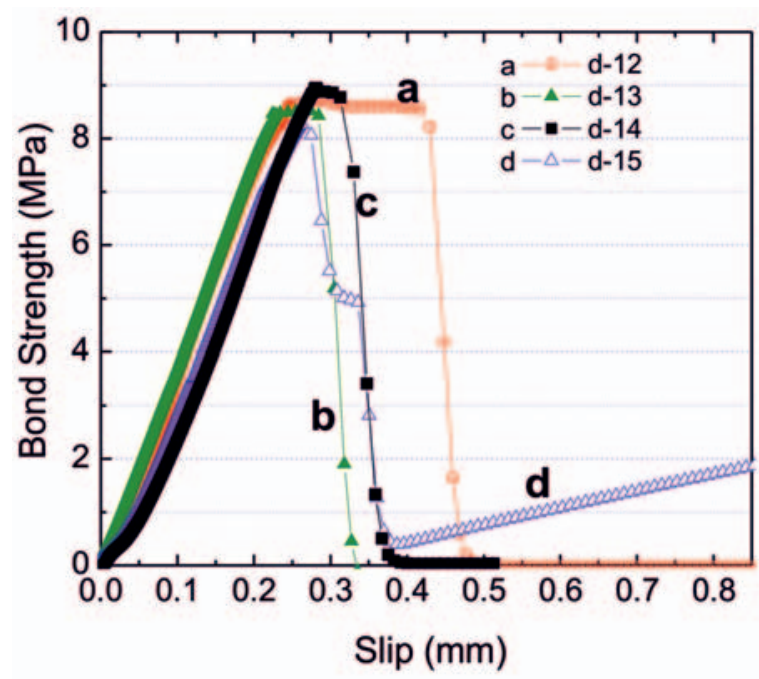

Figure 9. Bond stress versus slip of smooth ribbed bars with different internal diameter (a) $d-12$, (b) $d-13$, (c) $d-14$ and (d) $\mathrm{d}-15$. 


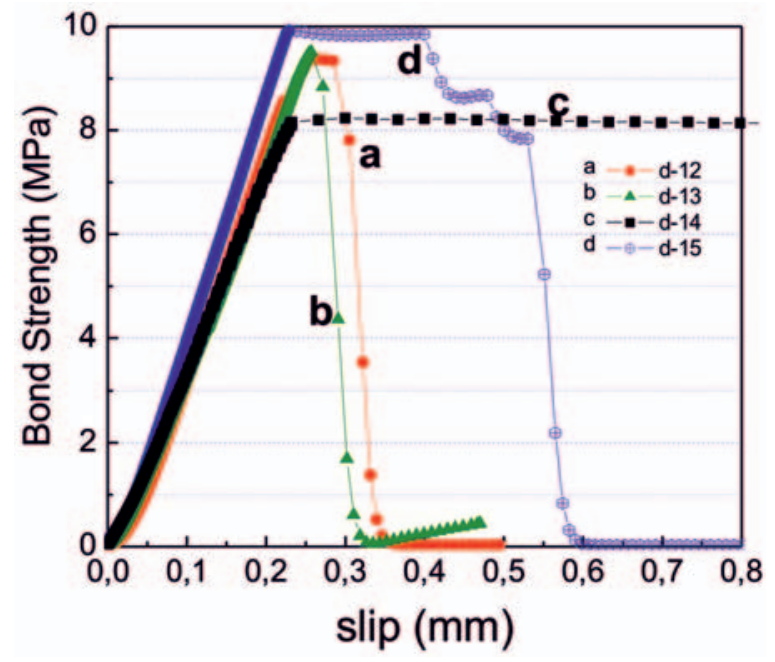

Figure 10. Bond stress versus slip of sanded ribbed bars (a) $d-12$, (b) $d-13$, (c) $d-14$ and (d) $d-15$.

The case of d-14 presents the lowest bond strength in the case of sanded bars. After it reaches the maximum, the curve presents an extended plateau due to frictional behavior (curve c). The splitting test confirms that bond failure happened within the interfaces of resin-rich layer and fibers inside.

\section{Conclusions}

The study of the bond behavior of glass fiber reinforced plastic (GFRP) embedded in concrete with different rib geometries was carried out. Regarding the width of the ribs, the results indicate that the bond strength is the highest when the failure mode is a combination of two mechanisms. Regarding the height of the ribs, the bond strength is independent of this parameter. In the case of sanded bars, it was found that the friction and interlock forces are more relevant, and the influence of the width of the ribs and the internal diameter is less important than in non-sanded bars.

Furthermore, it was demonstrated that a lot of work is necessary to identify an adequate parameter. It is necessary to provide an alternative to the as and CLR parameters described in the literature. It would need to characterize the influence of geometry surface on the bond stress between FRP and concrete.

\section{Funding}

This research received no specific grant from any funding agency in the public, commercial, or not-for-profit sectors.

\section{Acknowledgements}

This work was supported by Universidad de Buenos Aires, Argentina, Consejo Nacional de Investigaciones Científicas y Técnicas y la Agencia Nacional de Promoción Científica y Tecnológica.

\section{Conflict of Interest}

None declared.

\section{References}

1. Fib (Federation Internationale du Béton). FRP reinforcement in RC structures, Technical report prepared by a working party of Task Group 9.3. ISSN 1562-3610, 2007.

2. Bakis C, Uppuluriy V, Nannib A, et al. Analysis of bonding mechanisms of smooth and ribged FRP rods embedded in concrete. Compos Sci Technol 1998; 58: 1307-1319.

3. Piggott M. Load bearing fibre composites, 2th edn. Springer, 2001.

4. Ozden S and Akpinar E. Effect of confining FRP overlays on bond strength enhancement. Constr Build Mater 2007; 21: 1377-1389.

5. Al-Dulaijan S, Al-Zahrani M, Nanni A, et al. Effect of environmental pre-conditioning on bond of FRP reinforcement to concrete. J Reinf Plast Compos 2001; 20: 881-900.

6. Soong W, Raghavan J and Rizkalla S. Constr Build Mater 2011; 25: 2813-2821.

7. Federation Internationale du Beton. Bond in reinforcement in concrete. State of art. ISSN: 1562-3610. ISBN 2-88394-050-9, 2000, pp.3.

8. Cosenza E, Manfresi G and Realfonzo R. Analytical modeling of bond between FRP reinforcing bars and Concrete. Non metallic (FRP) reinforcement fot concrete structures. In: I Taerwe (ed.) C) RILEM. ISBN: 0419 20540 3, 1995.

9. Tighiouart B, Benmokrane B and Gao D. Investigation of bond in concrete member with fibre reinforced polymer (FRP) bars. Constr Build Mater 1998; 12: 453-462.

10. Benmokrane B, Zhang B and Chennouf A. Tensile properties and pullout behavior of AFRP and CFRP rods for grouted anchor applications. Constr Build Mater 2000; 14: $157-170$.

11. Ceroni F, Cosenza E, Gaetano M, et al. Durability issues of FRP rebars in reinforced concrete members. Cement Concr Compos 2006; 28: 857-868.

12. Lee $\mathrm{Y}, \mathrm{Kim} \mathrm{T}, \mathrm{Kim} \mathrm{T}$, et al. Interfacial bond strength of glass fiber reinforced polymer bars in high-strength concrete. Compos: Part B 2008; 39: 258-270.

13. Davalos J, Chen Y and Ray I. Effect of FRP bar degradation on interface bond with high strength concrete. Cement Concr Compos 2008; 30: 722-730.

14. Baena M, Torres L, Turon A, et al. Experimental study of bond behavior between concrete and FRP bars using a pull-out test. Compos: Part B 2009; 40: 784-797.

15. Al-mahmoud F, Castel A, Francois R, et al. Effect of surface pre-conditioning on bond of carbon fibre reinforced polymer rods to concrete. Cement Concr Compos 2007; 29: 677-689.

16. Morales Arias JP, Escobar M and Vazquez A. Surface treatments to improve bonding between GFRP bars and concrete. J Compos Mater. 